\title{
Effects of Biofeedback Postural Control Training on Weight distribution rate and Functional Ability in Stroke
}

\author{
Dae-JungYang \\ Department of physical therapy \\ Sehan University, Yeongam, Korea \\ Yo-Han Uhm \\ Department of physical therapy \\ Mokpo rehabilitation hospital, Mokpo, Korea
}

\begin{abstract}
This study examined the effects of biofeedback postural control training on the weight distribution rate and functional ability of subjects with stroke. A total of 30 stroke patients were enrolled in this study. Subjects were divided into a biofeedback postural training group (experimental group, $n=15$ ) and a dynamic balance training group (control group, $n=15$ ). Experimental subjects received biofeedback postural training and control subjects received dynamic balance training for 30 minutes per day, 5 times per week over a 6 week period. Weight distribution rate and functional ability were measured to identify the effect of the biofeedback postural training. Significant difference in weight distribution rate was observed in the experimental group, compared with the control group ( $p=0.05)$, and a significant difference in functional ability. The results of this study provide evidence in support of incorporating a biofeedback postural training for the improvement of weight distribution rate and functional ability of stroke patients.
\end{abstract}

Key words: Postural Control Training, Weight Distribution rate, Functional Ability.

\section{INTRODUCTION}

Stroke is a representative disease that causes disabilities, which degrades the quality of life as a persistent obstacle to survivors [1], and causes problems in functional activities [2]. Stroke patients show approximately two times larger postural sway than healthy persons when they move their weight within the bearing surface. To overcome the resultant instability, they move their weight to the non-paretic side, consequently reducing their balance ability due to uneven weight distribution occurring [3] because they place only $25 \sim 43 \%$ of the load on the paretic side [4]. For functional rehabilitation, the asymmetric weight bearing of the lower limbs should be evaluated before gait training and even weight bearing of the lower limb on the paretic side should be induced [5]. Functional ability is an essential ability defined by individuals for creating a meaningful life and maintaining physical and psychological well-being [6]. Among functional abilities, gaits are the most frequently used method of all moving methods and account for a large part of daily living activities [7]. Most stroke patients show changes in temporal and spatial gait

* Corresponding author,Email: uhmyo112@naver.com Manuscript received Aug. 01, 2013; revised Nov. 12, 2013; accepted Nov. 21, 2013 characteristics in comparison to healthy persons [8]. Among diverse therapeutic intervention methods for overcoming these unstable gait characteristics and reducing dependence on others in life, training using biofeedback has been recently reported as being quite effective on stroke patients [9]. Therapeutic interventions using biofeedback have advantages over other intervention methods such as relatively easier environment control and selection, the provision of training based on abilities through stepwise control of the level of task difficulty, the provision of fast and accurate sense feedback to task performance [10], and the provision of opportunities for selflearning in safe environments [11] Treatment using biofeedback is advantageous in that diverse environments can be provided to cause changes in sensory inputs thereby enhancing treatment effects for stroke patients [12], motivation for task accomplishment and active participation are enabled through diverse feedback mechanisms [13], and patients can be intensively trained on diverse target tasks necessary for the improvement of their functions [11]. Biofeedback plays important roles for patients with balance and gait disorders. The visual and perceptual elements of biofeedback have been said to be effective for stroke patients having difficulties in understanding the locational relationships between objects and spaces to improve balance and gait abilities [14]. Biofeedback has a weakness of being unable to appropriately control problems such as abnormal postural control occurring due to 
excessive effort required when tasks are performed and associative reactions. The purpose of the present study is to examine the effects of biofeedback postural control training on stroke patients' weight distribution rates and functional abilities in order to supplement the weakness of treatment using biofeedback.

\section{SUBJECTS AND METHODS}

\subsection{Subjects}

The subjects of this study were selected from among the patients who were diagnosed with stroke between January and March 2013 at M hospital located in Mokpo. The present study was conducted with 30 stroke patients (18 males and 12 females) whose dates of onset of stroke were at least one year earlier. Stroke patients for over one year and within two years are 25 persons, stroke patients for over two year and within three year are 5 persons. The patients provided written informed consent after being given a full explanation of the purposes of this study and the contents of the experiment. The criteria for participation of the subjects were as follows. Those who could walk at least $10 \mathrm{~m}$ independently, had no musculoskeletal disease that could affect the experiment, had no damage to hearing, the vestibular nerves, or the eyeball, had no neglect symptoms, could understand and follow instructions, and had sufficient abilities for communication and understanding to follow instructions during evaluation with 24 points or higher scores in the Mini-Mental State ExaminationKorean version (Table 1).

Table 1. General characteristics of the subjects

\begin{tabular}{|c|c|c|c|c|}
\hline & $\begin{array}{l}\text { BPCT } \\
(\mathrm{n}=15)\end{array}$ & $\begin{array}{l}\text { DBT } \\
(\mathrm{n}=15)\end{array}$ & \multirow[t]{2}{*}{$\mathrm{F}$} & \multirow[t]{2}{*}{$\mathrm{p}$} \\
\hline & Mean \pm SD & Mean \pm SD & & \\
\hline \multirow{2}{*}{ Gender } & Male 9 & Male 9 & & \\
\hline & Female 6 & Female 6 & & \\
\hline $\begin{array}{l}\text { Age } \\
\text { (year) }\end{array}$ & $\begin{array}{l}54.06 \pm \\
1.71\end{array}$ & $\begin{array}{l}52.60 \pm \\
1.90\end{array}$ & .286 & .597 \\
\hline $\begin{array}{l}\text { Height } \\
(\mathrm{cm})\end{array}$ & $\begin{array}{l}167.86 \pm \\
2.28\end{array}$ & $\begin{array}{l}169.60 \pm \\
2.30\end{array}$ & .082 & .777 \\
\hline $\begin{array}{l}\text { Weight } \\
(\mathrm{kg})\end{array}$ & $\begin{array}{l}63.93 \pm \\
2.11\end{array}$ & $\begin{array}{l}68.33 \pm \\
1.75\end{array}$ & .822 & .372 \\
\hline $\begin{array}{l}\text { Onset } \\
\text { (month) }\end{array}$ & $\begin{array}{l}16.06 \pm \\
0.80\end{array}$ & $\begin{array}{l}15.8 \pm \\
1.04\end{array}$ & 2.604 & .118 \\
\hline
\end{tabular}

BPCT: biofeedback postural control training

DBT: dynamic balance training

\subsection{Methods}

The study subjects received intervention by physical therapy for the nervous system that included muscle strengthening training and gait training for 30 minutes and the experimental group $(\mathrm{n}=15)$ additionally received biofeedback postural control training using Balance trainers (Medica
Medizintechink GmbH, Germany) for 30 minutes while the control group $(\mathrm{n}=15)$ received dynamic balance training removed of biofeedback using Balance trainers. The intervention was given for 30 minutes per time, five times per week for six weeks. The balance trainer used in the biofeedback postural control training has a mechanical joint with a degree of freedom of two and is connected to the subject with knee pads that support the knee and a pelvic support that stabilizes the pelvis. The mechanical joint of the postural control training machine allows physiological movements of the standing person while the person performs tasks and provides feedback of the degree of movements on the screen of the monitor connected to the machine [Figure 1].

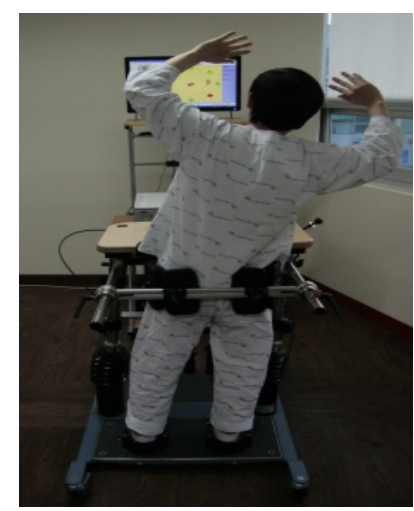

Fig. 1. Balance trainer

\subsection{Measurement tools}

The Biorescue (RM Ingenierie, France) for analyzing weight distribution rates consists of a movable rectangular force plate for standing with both feet and a graduated ruler is marked on the force plate for appropriate foot positions. The weight distribution rate of the weight supported by two feet. It is simple to measure, evaluates the variation in the ability to support body weight before and after treatment, and serves as standards that are useful for studying normal and abnormal posture [15]. Weight distribution rates were measured when the subject was standing on both feet in a natural posture looking at the monitor in front of him/her. In the evaluation, the resultant mean values were obtained by measuring weight distribution rates three times [Figure 2].

To measure functional abilities, timed 10 meter walking tests, timed up and go tests, and Berg Balance Scale tests were conducted. The timed 10 meter walking test is a test method of evaluating the gait velocity and balance of hemiplegic patients by measuring the time to walk a straight-line distance of $10 \mathrm{~m}$ which can be used as a scale of the recovery of mobility of hemiplegic patients [16]. The timed up and go test is for examining the dynamic balance ability and gait ability of hemiplegic patients. In this test, the time for the subject to stand up from a sitting position on a $46 \mathrm{~cm}$ high chair with armrests laid on a flat floor, go $3 \mathrm{~m}$, come back and sit on the chair again was measured three times and the average time was used [17]. Berg Balance Scale was developed by Berg K et al. [18] and can be used to objectively evaluate static and dynamic balance abilities. This scale is divided into three areas: sitting, standing up and postural changes. 


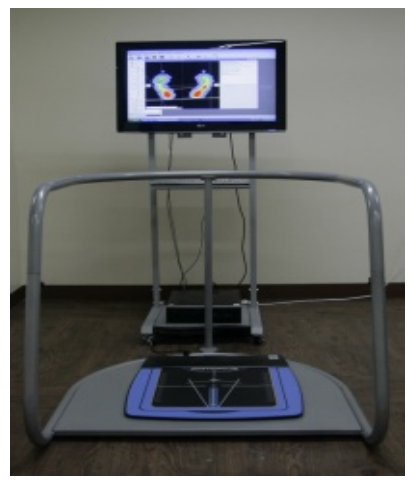

Fig. 2. Biorescue

\subsection{Statistical methods}

The data obtained in the present study were statistically processed using SPSS Windows 17.0. Analyses of covariance (ANCOVA) were conducted to compare weight distribution rates and functional abilities between different intervention methods. All the statistical significance levels used were 0.05 .

\section{RESULTS}

The weight distribution rates on the paretic side of the biofeedback postural control training group and the dynamic balance training group before and after the intervention were compared. The results showed significant differences in both groups as the rates were changed from $44.83 \pm 3.54 \%$ to $46.80 \pm 4.28 \%$ in the biofeedback postural control training group and from $45.26 \pm 1.87 \%$ to $46.28 \pm 6.61 \%$ in the dynamic balance training group $(\mathrm{p}<0.05)$.

The functional abilities of the biofeedback postural control training group and the dynamic balance training group before and after the intervention were compared. The results showed significant differences in the timed 10 meter walking tests in both groups as the times changed from $33.16 \pm 9.54$ seconds to $28.74 \pm 5.28$ seconds in the biofeedback postural control training group and from $31.98 \pm 2.67 \mathrm{sec}$. to $28.28 \pm 4.27$ seconds in the dynamic balance training group. The results showed significant differences in the timed up and go tests in both groups as the times changed from $21.01 \pm 2.04$ seconds to $17.61 \pm 1.92$ seconds in the biofeedback postural control training group and from $20.80 \pm 9.47$ seconds to $18.94 \pm 7.53$ seconds in the dynamic balance training group. The results also showed significant differences in the Berg Balance Scale in both groups as the times changed from $42.13 \pm 3.49$ seconds to $47.86 \pm 2.47$ seconds in the biofeedback postural control training group and from $42.80 \pm 3.07$ seconds to $44.93 \pm 2.57$ seconds in the dynamic balance training group $(\mathrm{p}<.001)($ Table 2$)$. The average values of pre-tests were slightly different statistically but, according to the homogeneity test, did not show the significant differences.

Table 2. A comparison of measurements between pre- and postintervention each group

\begin{tabular}{|c|c|c|c|c|c|}
\hline \multirow[b]{2}{*}{ Test } & \multicolumn{2}{|c|}{ BPCT Group } & \multicolumn{2}{|c|}{ DBT Group } & \multirow[b]{2}{*}{$\mathrm{p}$} \\
\hline & $\begin{array}{l}\text { Pre- } \\
\text { test }\end{array}$ & $\begin{array}{l}\text { Post- } \\
\text { test }\end{array}$ & $\begin{array}{l}\text { Pre- } \\
\text { Test }\end{array}$ & $\begin{array}{l}\text { Post- } \\
\text { test }\end{array}$ & \\
\hline
\end{tabular}

\begin{tabular}{llllll}
\hline WD & $44.83 \pm$ & $46.80 \pm$ & $45.26 \pm$ & $46.28 \pm$ & .011 \\
$(\%)$ & 3.54 & 4.28 & 1.87 & 6.61 & \\
& & & & & \\
10MWT & $33.16 \pm$ & $28.74 \pm$ & $31.98 \pm$ & $28.38 \pm$ & .000 \\
$(\mathrm{sec})$ & 9.54 & 5.28 & 2.67 & 4.27 & \\
& & & & & \\
TUGT & $21.01 \pm$ & $17.61 \pm$ & $20.80 \pm$ & $18.94 \pm$ & .000 \\
(sec) & 2.04 & 1.92 & 9.47 & 7.53 & \\
BBS & $42.13 \pm$ & $47.68 \pm$ & $42.80 \pm$ & $44.93 \pm$ & .000 \\
(score) & 3.49 & 2.47 & 3.07 & 2.57 & \\
\hline
\end{tabular}

The values with same word are significant differences $(\mathrm{p}<0.05)$ by ANCOVA test.

BPCT: biofeedback postural control training

DBT: dynamic balance training

WD: weight distribution, 10MWT: $10 \mathrm{~m}$ walking test, TUGT: timed up and go test, BBS: berg balance scale

\section{DISCUSSION}

Due to abnormal postural control, stroke patients show large postural sway when moving their weight and show reduced ability to maintain stable postures within bearing surfaces. As a result, their reduced balance ability restricts their functional activities [2]. Kim [19] revealed that weight moving training through visual feedback enhanced the weight distribution rate of the paretic side of the patients and gait velocity of the patients. The present study confirmed that the group receiving biofeedback postural control training showed significant increases in weight distribution rates and gait abilities. It's considered postural control training using biofeedback promotes motor learning so weight distribution rate and gait ability increase. Van Peppen et al. [20] reported that when balance trainings using general physical therapy and visual biofeedback were implemented, biofeedback based balance training showed significant increases in weight distribution rates and temporal variables. This report was also consistent with the results of the current study in that both weight distribution rates and functional gait abilities improved in the biofeedback postural control training group. The weight distribution rates and functional gait abilities are considered to have improved because information on the subjects' movements while they were performing dynamic tasks was provided and used as feedback to lead immediate behavioral revision in the performance of the next movement. In a study conducted to improve stroke patients' motility, Heller et al. [21] reported that the patients' gait ability improved more in training using visual and perceptual biofeedback compared to general physical therapy for the nervous system. In the present study the postural control training group based on biofeedback also showed significant differences in timed 10 meter walking tests and timed up and go tests. In the results of a study of the effects of virtual reality on stroke patients, Walker et al. [22] demonstrated that the Berg balance scale score increased from 43.8 to 48.8 . The results of the present study also showed increases in Berg balance scale scores as with the previous 
study. Given these results, biofeedback training is considered to be related to weight distribution rates and functional abilities.

In the present study, the effects of biofeedback postural control training of stroke patients on their weight distribution rates and functional abilities of their paretic side were analyzed and the results indicated that biofeedback postural control training was more effective for the improvement of the weight distribution rates and functional abilities of the lower limb. Therefore, if biofeedback postural control training is added to general physical therapy, stroke patients' rehabilitation effects can be enhanced further. Thus, biofeedback postural control training using sight and perception should be actively utilized in treatment of stroke patients in clinics.

\section{ACKNOWLEDGEMENT}

This work was supported by Sehan University Foundation Grant, 2013.

\section{REFERENCES}

[1] J. E. Harris, J. J. Eng, D. S. Marigold, C. D. Tokuno, and C.L Louis, "Relationship of balance and mobility to fall incidence in people with chronic stroke," Phys Ther, vol. 85 , no. 2, 2005, pp. 150-158.

[2] N. Teasdale and M. Simoneau, "Attentional demands for postural control: the effects of aging and sensory reintegration," Gait \& Posture, vol. 14, 2001, pp. 203-210.

[3] B. Belgen, M. Beninato, P. E. Sullivan, and K. Narielwalla, "The association of balance capacity and falls self-efficacy with history of falling in community-dwelling people with chronic stroke," Arch Phys Med Rehabil, vol. 87 no. 4, 2006, pp. 554-561.

[4] B. J. Kim, B. K. Hwang, and S. S. Bae, "The improve of hemiplegic patients functional ambulation profile by forceful respiratory exercise," J Korean Soc Phys Ther, vol. 16, no.1, 2004, pp. 13-24.

[5] H. C. Kwan and D. H Jung, "A study of influence of asymmetrical weight bearing on the LOS of independent ambulatory hemiparetic patients on standing," Korean Academy of University Trained Physical Therapists, vol. 7, no. 2, 2000, pp. 1-19.

[6] S. B. O'Sullivan and T. J. Schmitz, Physical rehabilitation, 5th ed, Philadelphia: F.A Davis company, 2007, p.373.

[7] M. De-harrt, A. C. Geurts, S. C. Huidekoper, L. Fasotti, and J. van Limbeek, "Recovery of standing balance in post acute stroke patients: A rehabilitation cohort study," Arch Phys Med Rehabil, vol. 85, no. 6, 2001, pp. 886-895.

[8] J. H. Kim and T. R. Han, Rehabilitation medicine, 2nd ed, Seoul: KOONJA pubilishing, 2002, pp. 49-73.

[9] G. Kwakkel, B. J. Kollen, and R. C. Wagenaar, "Long term effects of intensity of upper and lower limb training after stroke: a randomised trial," J Neurol Neurosurg Psychiatry, vol. 72, 2002, pp. 473-479.

[10] R. C. Wagenaar, M. P. Ford, K. M. Newell, "The effect of auditory rhytnms and instruction on walking patterns in individuals post stroke," Gait \& Posture, vol. 26, no. 1, 2007, pp. 150-155.

[11] L. M. Katz, I. O. Sender, and Z. Dvir, "The influence of early cycling training on balance in stroke patients at the subacute stage," ClinRehabil, vol. 20, 2006, pp. 298-405.

[12] A. A. Rizzo, J. G. Buckwalter, and U. Neumann, "Virtual reality and cognitive rehabilitation: A brief review of the future," J head trauma Rehabil, vol. 12, no. 6, 1997, pp. 115.

[13] D. Jack, R. Boian, A. S. Merians, M. Tremain, G. C. Burdea, S. V. Adamovich, M. Recce, and H. Poizer, "Virtual reality-enhanced stroke rehabilitation," IEEE Trans Rehabil Eng, vol. 9, 2001, pp. 308-318.

[14] A. Leroux, I. I. Pinet I, and S. Nadeau, "Task-oriented intervention in chronic stroke: changes in clinical and laboratory measures of balance and mobility," Am J Phys Med Rehabil, vol. 85, no. 10, 2006, pp. 820-830.

[15] H. Y. Ju, Effects of differences in shoulder height, leg length and foot arch height on weight distribution, Department of Physical Therapy Graduate School of Dongshin University, 2008.

[16] C. M. Dean, C. L. Richards, and F. Malouin, "Walking speed over 10 meters overestimates locomotor capacity after stroke," Clin Rehabil, vol. 15, no. 1, 2001, pp. 415421.

[17] D. Podsiadlo and S. Richardson, "The timed up \& go: A test of basic functional mobility for frail elderly persons," J Am Geriatr Soc, vol. 39, 1991, pp. 142-148.

[18] K. Berg, S. Wood-Dauphinee, J. I. Williams, and G. David, "Measuring balance in the elderly: preliminary develop ment of an instrument," Physiotherapy Canada, vol. 41, 1989, pp. 304-311.

[19] K. C. Kim, The effect of weight transfer training using visual feedback program on balance and gait in patient with stroke, Department of Physical Therapy Graduate School of Yongin University, 2009.

[20] R. P. Van Peppen, M. Kortsmit, E. Lindeman, and G. Kwakkel, "Effects of visual feedback therapy on postural control in bilateral standing after stroke: a systematic review," J Rehabil Med, vol. 38, no. 1, 2006, pp. 3-9.

[21] F. Heller, B. F. Beuret, and J. Weber, "Postural bio feedback and locomotion reducation in stroke patients," Ann Readapt Med Phys, vol. 48, no. 4, 2005, pp. 187-195.

[22] M. L. WalkerL, S. I. Ringleb, G. C. Maihafer, R. Walker, J. R. Crouch, B. Van Lunen, and S. Morrison, "Virtual Realityenhanced partial body weight-supported treadmill training post stroke: feasibility and effectiveness in 6 subjects," Arch Phys Med Rehabil, vol. 91, 2010, pp. 115-122.

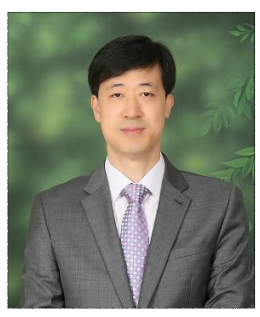

Dae-JungYang

He received the degree of M.S. in the department of physiotherapy from Daebul university of Korea in 2004 and a Ph. $\mathrm{D}$ in the department of physiotherapy from Dongshin university of Korea in 2011. His main research interests were manual therapy and clinical kinesiology. 


\section{Yo-Han Uhm}

He received the degree of M.S. in the department of physiotherapy from Se-han university of Korea in 2013. He works for Mokpo rehabilitation hospital. His main research interests were neurological physical therapy and therapeutic exercise. 